\title{
PENGARUH JUMLAH LAMPU TERHADAP HASIL TANGKAPAN PUKAT CINCIN MINI DI PERAIRAN PEMALANG DAN SEKITARNYA
}

\author{
Erfind Nurdin \\ Peneliti pada Balai Riset Perikanan Laut, Muara Baru-Jakarta \\ Teregristrasi I tanggal: 16 Mei 2006; Diterima setelah perbaikan tanggal: 20 Maret 2007; \\ Disetujui terbit tanggal: 1 Agustus 2007
}

\begin{abstract}
ABSTRAK
Penelitian tentang pengaruh jumlah lampu terhadap hasil tangkapan pukat cincin mini di perairan utara Jawa Tengah khususnya di Pemalang dilakukan pada bulan September 2004. Dalam pengoperasiaan, selain menggunakan rumpon juga digunakan cahaya sebagai alat bantu penangkapan. Pengukuran nilai intensitas cahaya lampu dilakukan dengan meggunakan LI COR 250 quantum meter ( $\mu \mathrm{mol} \mathrm{s}-1 \mathrm{~m}^{-2}$ ) pada intensitas atau jumlah lampu yang berbeda @ 400 watt (2 galaksi, 5 mercury), (6 mercury), dan (2 galaksi, 6 mercury). Jumlah hasil tangkapan pukat cincin mini di perairan utara Jawa tengah $3.393,5 \mathrm{~kg}$ dengan laju tangkap (catch rate) 125,7 kg per tawur. Komposisi hasil tangkapan didominasi oleh ikan tembang $(60,4 \%$ dari jumlah hasil tangkapan keseluruhan), diikuti layur (11,3\%), cumi (8,8\%), tongkol $(6,7 \%)$, bawal $(3,0 \%)$, kembung $(2,7 \%)$, tetengkek $(2,2 \%)$, dan lain-lain (kurang dari $2 \%)$. Uji statistik menunjukkan penggunaan jumlah lampu 6,7 , dan 8 buah tidak berpengaruh nyata pada hasil tangkapan ikan.
\end{abstract}

\section{KATA KUNCI: pukat cincin, intensitas cahaya, hasil tangkapan, Pemalang}

\section{PENDAHULUAN}

Di Pemalang, Jawa Tengah banyak nelayan mengoperasikan pukat cincin mini. Beberapa antara lain sudah dilengkapi dengan alat bantu penangkapan berupa cahaya lampu (light fishing) yang berfungsi untuk memikat ikan. Menurut Ayodhyoa (1981), peristiwa berkumpulnya ikan di bawah sumber cahaya disebabkan mempunyai sifat fototaksis positif atau karena ada makanan.

Pada saat ini armada pukat cincin di Pemalang semakin berkembang khusus dalam hal penggunaan lampu sebagai sumber cahaya terutama dalam hal jumlah lampu atau kekuatan (daya) lampu. Aktivitas perikanan pukat cincin di Laut Jawa mengindikasikan semakin jauh jangkauan daerah penangkapannya sejak tahun 1990-an yang diikuti oleh meningkat jumlah armada yang ada. Dampak yang ditimbulkan antara lain ditunjukkan oleh menurunnya produktivitas pukat cincin di daerah tersebut.

Di Indonesia, armada pukat cincin berkembang pesat sejak pelarangan operasi traw/ pada tahun 1980 dan mencapai puncak pada tahun 1985 dengan jumlah 520 unit. Ukuran kapal maupun alat tangkap terus bertambah besar dari tahun ke tahun, sehingga dapat menjangkau daerah penangkapan (fishing ground) yang semakin jauh (Wijopriono et al., 1995).
Alat bantu cahaya digunakan oleh nelayan pada unit penangkapan yang berbeda. Besaran intensitas cahaya yang digunakan sangat tergantung pada jenis alat tangkap, sasaran penangkapan, daerah penangkapan, dan kemampuan modal usaha. Pada perikanan pukat cincin sumber cahaya berasal dari tenaga listrik generator dengan jenis lampu flourescent. Terkait dengan penggunaan alat bantu cahaya, terdapat kecenderungan penggunaan intensitas cahaya yang semakin besar dalam operasi penangkapan berbagai jenis alat tangkap, ditunjukkan oleh kompetisi di antara kapal-kapal pukat cincin di Laut Jawa dalam penggunaan cahaya pada saat ini semakin tinggi. Hasil penelitian menunjukkan beberapa kapal pukat cincin sudah menggunakan lampu flourescent dengan kekuatan $30 \mathrm{Kw}$. (Sadhotomo \& Pottier, 1995). Nelayan beranggapan bahwa semakin tinggi intensitas cahaya yang digunakan, semakin besar kelompok ikan yang dapat dikumpulkan.

\section{DESKRIPSI KAPAL DAN JARING}

Secara umum, nelayan pukat cincin di Pemalang menggunakan 2 jenis kapal yang berbeda yaitu kapal jaring sebagai penangkap ikan dan kapal lampu yang berfungsi sebagai kapal bantu yang jumlahnya antara 3 sampai dengan 4 buah. 
Kapal jaring pada umumnya terbuat dari bahan kayu dengan ukuran panjang $12 \mathrm{~m}$, lebar 3,5 $\mathrm{m}$, dan dalam 1,2 m bermesin diesel 24 HP dengan jumlah anak buah kapal antara 17 sampai dengan 20 orang. Kapal lampu terbuat dari kayu dengan panjang $10 \mathrm{~m}$, lebar 2,25 m, dan dalam $1 \mathrm{~m}$, dilengkapi dengan 2 lampu galaksi (@ 400 watt) dan 5 sampai dengan 6 lampu mercury (@ 400 watt), bermesin diesel 24 HP dengan jumlah anak buah kapal 3 orang. Pemanfaatan cahaya sebagai alat bantu penangkapan ini didasarkan pada sifat fototaksis positif dari ikan-ikan pelagis kecil yang menjadi tujuan utama penangkapan.

Deskripsi pukat cincin di Pemalang terdiri atas 2 bagian utama yaitu sayap dan kantong. Bagian kantong terletak di tengah yang diapit bagian sayap pada ke-2 sisi dengan ukuran yang sama besar. Jaring berukuran panjang $280 \mathrm{~m}$ dan dalam $13 \mathrm{~m}$ (Gambar 1).

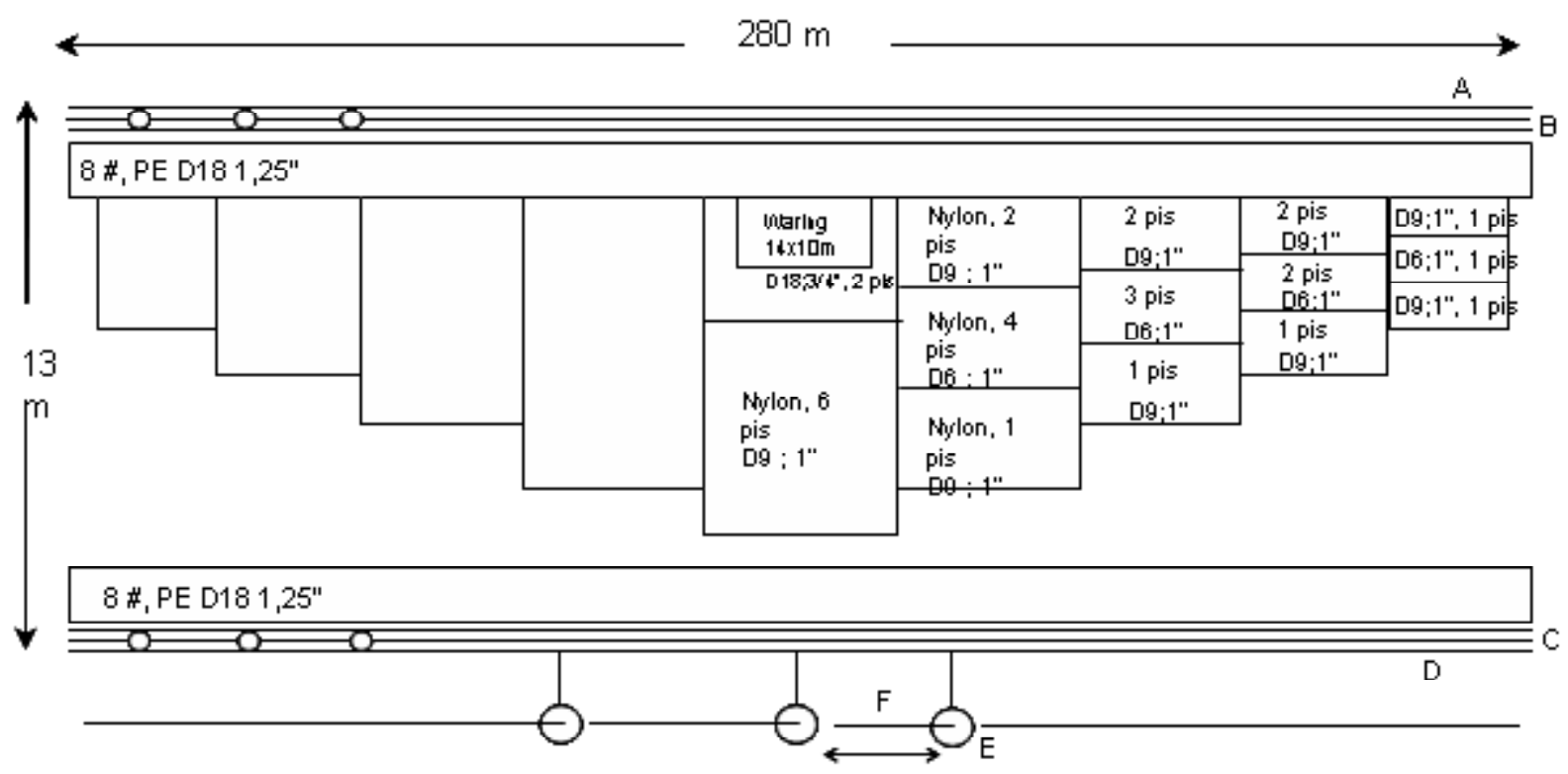

Gambar 1 Desain pukat cincin mini di Pemalang.

Keterangan: A. Tali ris atas PE $\varnothing 6 \mathrm{~mm}$; B. Tali pelampung $280 \mathrm{~m}, \mathrm{PE} \varnothing 6 \mathrm{~mm}$, pelampung tipe Y-50 (brown) dan A-8 (white, jarak antar pelampung 20 sampai dengan $25 \mathrm{~cm} ; \mathrm{C}$. Tali ris bawah PE $\varnothing 6 \mathrm{~mm}$; D. Tali pemberat $280 \mathrm{~m}, \mathrm{PE} \varnothing 10 \mathrm{~mm}$, pemberat timah $@=125 \mathrm{~g}$ ), jarak antar pemberat $20 \mathrm{~cm}$; E. Cincin kuningan $\varnothing 15 \mathrm{~cm}$, tali kolor 350 $\mathrm{m}, \mathrm{PE} \varnothing 25 \mathrm{~mm}$; F. Jarak antar cincin 3 sampai dengan $4 \mathrm{~m}$

\section{Daerah Penangkapan}

Pengamatan tentang cara dan daerah pengoperasian serta komposisi hasil tangkapan pukat cincin mini yang berbasis di Pemalang dilakukan pada bulan September dan Oktober 2004. Daerah penangkapan ikan terdapat di perairan sebelah utara Jawa Tengah pada posisi geografis antara S $06^{\circ} 44,005^{\prime}-E$ $109^{\circ} 19,285^{\prime}$, dengan jarak antara 10 sampai dengan 30 mil dari pantai dengan waktu tempuh antara 3 sampai dengan 4 jam (Gambar 2).

\section{Intensitas Cahaya}

Intensitas sebaran cahaya diukur menggunakan quantum meter dengan satuan $\mu$ mol per detik per meter persegi $\left(\mu \mathrm{mol} \mathrm{s} \mathrm{s}^{-1} \mathrm{~m}^{-2}\right.$ ). Di dalam air kuat intensitas cahaya sangat dipengaruhi oleh keadaan perairan seperti kecerahan, arus, dan gelombang. Sebaran cahaya yang berasal dari kapal dengan lampu galaksi 2 buah dan mercury 5 buah, dan mercury 6 buah, serta galaksi 2 buah dan mercury 6 buah menunjukkan pola sebaran yang sama (Gambar 3). 


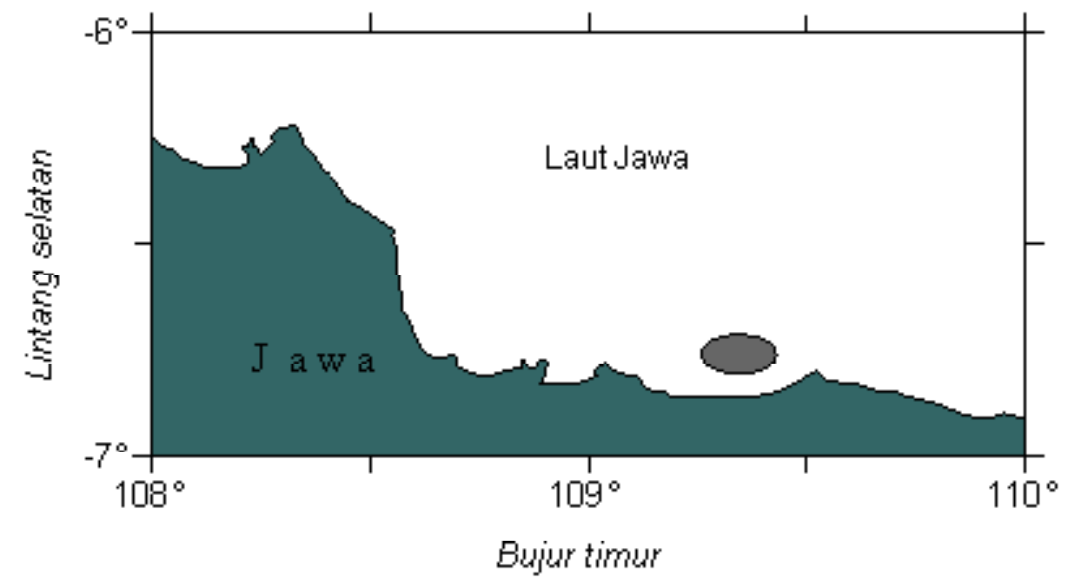

Gambar 2. Lokasi penangkapan pukat cincin mini di utara Jawa Tengah.

Sebaran vertikal, dengan jarak $2 \mathrm{~m}$ dari sumber cahaya pada kedalaman $1 \mathrm{~m}$ menunjukkan intensitas cahaya perahu (lampu galaksi 2 buah dan mercury 5 buah) $0,33 \mu \mathrm{mol} \mathrm{s}^{-1} \mathrm{~m}^{-2}$ dan mencapai titik nol pada kedalaman $27 \mathrm{~m}$. Perahu dengan lampu mercury 6 buah dengan jarak $3 \mathrm{~m}$ dari sumber cahaya pada kedalaman $1 \mathrm{~m}$ menghasilkan intensitas cahaya 0,064 $\mu \mathrm{mol} \mathrm{s} \mathrm{s}^{-1} \mathrm{~m}^{-2}$ dan mencapai titik nol pada kedalaman $16 \mathrm{~m}$. Sedangkan perahu dengan lampu galaksi 2 buah dan mercury 6 buah dengan jarak $3 \mathrm{~m}$ dari sumber cahaya pada kedalaman $1 \mathrm{~m}$ memiliki intensitas cahaya $0,33 \mu \mathrm{mol} \mathrm{s} \mathrm{m}^{-1} \mathrm{~m}^{-2}$ dan mencapai titik nol pada kedalaman $15 \mathrm{~m}$.

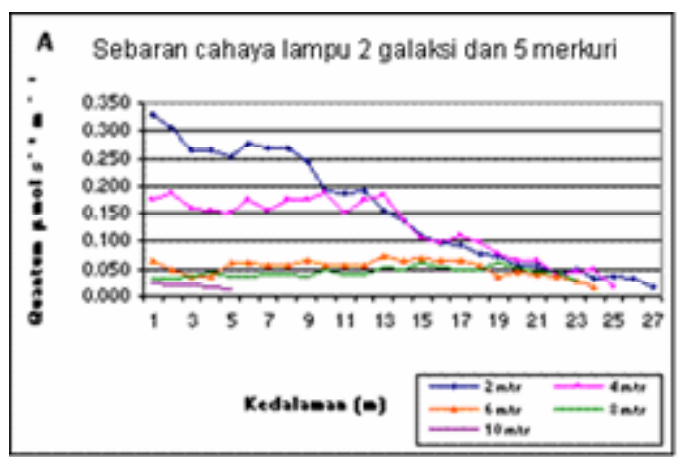

Sebaran cahaya secara horizontal, dengan jarak $10 \mathrm{~m}$ dari pusat cahaya pada perahu lampu galaksi 2 buah dan mercury 5 buah dengan kedalaman $5 \mathrm{~m}$ menunjukkan kuat cahaya $0,014 \mathrm{\mu mol} \mathrm{s}^{-1} \mathrm{~m}^{-2}$. Perahu dengan lampu mercury 6 buah pada jarak $9 \mathrm{~m}$ dari pusat cahaya dengan kedalaman $2 \mathrm{~m}$ menunjukkan kuat cahaya $0,014 \mu \mathrm{mol} \mathrm{s}^{-1} \mathrm{~m}^{-2}$. Sedangkan perahu dengan lampu galaksi 2 buah dan mercury 6 buah dengan jarak $7 \mathrm{~m}$ dari pusat cahaya pada kedalaman menunjukkan kuat cahaya $0,014 \mu^{m o l ~ s}{ }^{-1} \mathrm{~m}^{-2}$.

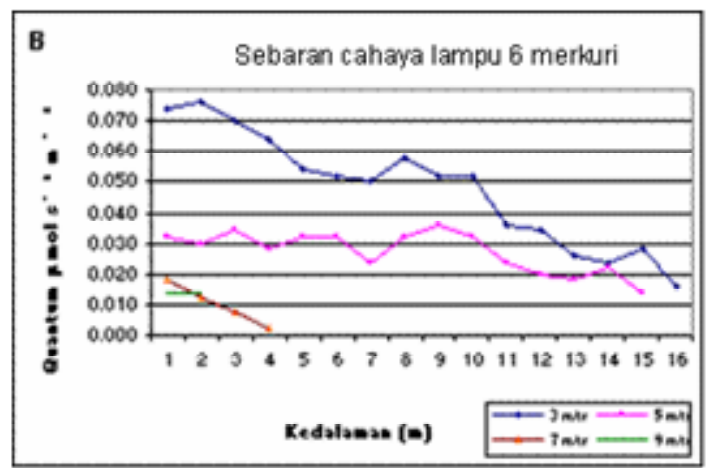

Gambar 3. Sebaran cahaya di dalam air pada unit mini purse seine.

Keterangan: A. Perahu dengan lampu galaksi 2 buah dan mercury 6 buah @ 400 watt; B. Perahu dengan lampu mercury 6 buah @ 400 watt; C. Perahu dengan lampu galaksi 2 buah dan mercury 5 buah @ 400 watt 


\section{Hasil Tangkapan}

Jumlah hasil tangkapan dari 27 ulangan tawur $3.393,5 \mathrm{~kg}$ dengan laju tangkap (catch rate) $125,7 \mathrm{~kg}$ per tawur. Pengambilan contoh biologi meliputi panjang dan bobot individu dilakukan terhadap 6 spesies ikan pelagis yang dominan, yaitu tetengkek
(Megalaspis cordyla) 36 ekor, kembung (Rastreliger brachyoma) 177 ekor, tembang (Sardinella fimbriata) 79 ekor, bentong (Selaroides boops) 30 ekor, selar kuning (Selaroides leptolepis) 144 ekor, dan bawal hitam (Formio niger) 48 ekor. Hasil pengukuran terhadap panjang cagak (FL) dan bobot (W) masingmasing jenis ikan tersebut dapat dilihat pada Tabel 1.

Tabel 1. Panjang dan bobot ikan dominan tertangkap dengan pukat cincin mini di perairan utara Jawa Tengah, bulan September 2004

\begin{tabular}{clcccc}
\hline \multirow{2}{*}{ No. } & \multirow{2}{*}{ Jenis } & \multicolumn{2}{c}{ Panjang cagak $(\mathbf{c m})$} & \multicolumn{2}{c}{ Bobot $(\mathbf{g})$} \\
\cline { 3 - 6 } & Kisaran & Rata-rata & Kisaran & Rata-rata \\
1. & Kembung & $8-9$ & 10,68 & $10-25$ & 15 \\
2. & Tetengkek & $16-26$ & 20,44 & $10-20$ & 14 \\
3. & Tembang & $9-11$ & 9,62 & $13-17$ & 15 \\
4. & Bentong & $17-24$ & 19,87 & $14-40$ & 19 \\
5. & Selar & $10-20$ & 12,42 & $10-45$ & 29 \\
6. & Bawal & $18-28$ & 21,17 & $165-670$ & 325 \\
\hline
\end{tabular}

Dari hasil tangkapan setiap tawur terlihat bahwa jumlah ikan hasil tangkapan bervariasi pada setiap jumlah lampu. Pada kapal dengan jumlah lampu 6 buah menunjukkan hasil tangkapan tertinggi $(182 \mathrm{~kg})$ dan terendah $(9 \mathrm{~kg})$ dengan rata-rata $77 \mathrm{~kg}$. Kapal dengan jumlah lampu 7 buah menunjukkan hasil tangkapan tertinggi $(562 \mathrm{~kg})$ dan terendah $(23 \mathrm{~kg})$ dengan rata-rata $147 \mathrm{~kg}$. Kapal dengan jumlah lampu 8 buah menunjukkan hasil tangkapan tertinggi (638 $\mathrm{kg})$ dan terendah $(48 \mathrm{~kg})$ dengan rata-rata $151 \mathrm{~kg}$ (Tabel 2).

Total hasil tangkapan keseluruhan dari 27 kali tawur $3.393,5 \mathrm{~kg}$. Komposisi hasil tangkapan menunjukkan ikan tembang merupakan hasil tangkapan terbesar yaitu $2.049,5 \mathrm{~kg}(60,4 \%$ dari total hasil tangkapan keseluruhan), diikuti layur $11,3 \%$, cumi $8,8 \%$, tongkol
$6,7 \%$, bawal 3,0\%, kembung 2,7\%, tetengkek 2,2\%, dan lain-lain kurang dari $2 \%$ (Tabel 3 ).

Analisis sidik ragam terhadap pengaruh jumlah lampu pada hasil tangkapan dilakukan dari 3 perlakuan (6, 7, dan 8 lampu) dengan 9 kali ulangan untuk setiap perlakuan. Total hasil tangkapan pada tiap perlakuan berbeda (Tabel 4). Pada perhitungan selanjutnya dilakukan transformasi data $\sqrt{(y+0,5)}$ terhadap nilai setiap ulangan, sehingga diperoleh hasil analisis sebagaimana ditunjukkan pada Tabel 5 .

Analisis sidik ragam menunjukkan perbedaan jumlah lampu pada setiap perlakuan tidak berbeda nyata $\left(\mathrm{F}_{\text {nitung }}<\mathrm{F}_{\text {tabel }} 5 \%\right)$, dengan kata lain ke-3 perlakuan tersebut dalam pengoperasian akan mendapatkan hasil tangkapan yang secara nyata tidak berbeda (Tabel 5). 
Tabel 2. Jumlah dan persentase hasil tangkapan dalam 27 kali tawur

\begin{tabular}{|c|c|c|c|c|c|c|c|c|c|c|c|c|c|}
\hline \multirow{2}{*}{$\begin{array}{l}\text { Jumlah } \\
\text { lampu }\end{array}$} & \multirow[b]{2}{*}{ No. } & \multirow{2}{*}{$\begin{array}{c}\text { Hasil } \\
(\mathrm{kg})\end{array}$} & \multicolumn{11}{|c|}{ Persentase hasil tangkapan (\%) } \\
\hline & & & Tembang & Layur & Cumi & Tongkol & Bawal & Kembung & Selar & Tengkek & Teri & Bentong & $\begin{array}{l}\text { Lain- } \\
\text { lain }\end{array}$ \\
\hline & 1 & 182 & 82,4 & & & & & 6,6 & 2,2 & 3,3 & 5,5 & & \\
\hline & 2 & 54 & 46,3 & & & & & 5,6 & 37,0 & 5,6 & 5,6 & & \\
\hline & 3 & 105,5 & 71,1 & & 5,7 & & & 5,7 & & 11,9 & & 5,7 & \\
\hline & 4 & 75 & 100,0 & & & & & & & & & & \\
\hline & 5 & 50 & 50,0 & & 38,0 & & & 12,0 & & & & & \\
\hline & 6 & 80 & 31,3 & & 47,5 & & 21,3 & & & & & & \\
\hline
\end{tabular}

6

\begin{tabular}{|c|c|c|c|c|c|c|c|c|c|c|c|c|c|}
\hline & 7 & 77 & 13,0 & 52,0 & 20,8 & & 9,1 & & & & & & 5,2 \\
\hline & 8 & 9 & 22,2 & & 33,3 & & & & 22,2 & & & & 22,2 \\
\hline & 9 & 68 & 36,8 & 54,4 & 8,8 & & & & & & & & \\
\hline rata-rata & & 77,83 & & 50,3 & 53,2 & 25,7 & - & 15,2 & 7,5 & 20,5 & 6,9 & 5,5 & 5,7 \\
\hline & 1 & 227 & 66,1 & & & & 14,1 & & & 8,8 & 11,0 & & \\
\hline & 2 & 59,5 & 42,0 & & & & 21,9 & 16,8 & & 19,3 & & & \\
\hline & 3 & 119,5 & 31,4 & & 15,1 & & & 10,5 & 20,9 & 16,7 & & 5,4 & \\
\hline & 4 & 23 & & & 100,0 & & & & & & & & \\
\hline 7 & 5 & 55 & 45,5 & & 29,1 & & 25,5 & & & & & & \\
\hline & 6 & 176 & & 45,5 & 25,0 & 25,6 & 4,0 & & & & & & \\
\hline & 7 & 562 & 93,4 & & & 4,5 & & 1,3 & & & & & 0,9 \\
\hline & 8 & 85 & 88,2 & & & & & 11,8 & & & & & \\
\hline & 9 & 23 & & & 69,6 & & & & & & & 30,4 & \\
\hline rata-rata & & 147,78 & & 61,1 & 45,5 & 47,7 & 15,0 & 16,4 & 10,1 & 20,9 & 15,0 & 11,0 & 17,9 \\
\hline & 1 & 100 & 100,0 & & & & & & & & & & \\
\hline & 2 & 57 & & 43,9 & 35,1 & & 10,5 & & & & & 10,5 & \\
\hline & 3 & 56 & & 44,6 & 48,2 & & & & 7,1 & & & & \\
\hline & 4 & 48 & & 52,1 & 47,9 & & & & & & & & \\
\hline 8 & 5 & 117 & & 64,1 & 8,6 & & 6,0 & & 21,4 & & & & \\
\hline & 6 & 158 & 47,5 & 47,5 & 5,1 & & & & & & & & \\
\hline & 7 & 96 & & & & 100,0 & & & & & & & \\
\hline & 8 & 93 & & & 6,5 & 66,7 & & 26,9 & & & & & \\
\hline & 9 & 638 & 98,0 & & & & & & & & & & 2,0 \\
\hline rata-rata & & 151,44 & & 81,8 & 50,4 & 25,2 & 83,3 & 8,3 & 26,9 & 14,3 & - & - & 10,5 \\
\hline
\end{tabular}

Tabel 3. Komposisi hasil tangkapan pukat cincin mini di perairan utara Jawa Tengah, bulan September 2004

\begin{tabular}{|c|c|c|c|}
\hline No. & Jenis ikan & Bobot (kg) & $\%$ \\
\hline 1. & Tembang & $2.049,5$ & 60,4 \\
\hline 2. & Layur & 382 & 11,3 \\
\hline 3. & Cumi & 299 & 8,8 \\
\hline 4. & Bawal & 103 & 3,0 \\
\hline 5. & Tetengkek & 73 & 2,2 \\
\hline 6. & Bentong & 25,5 & 0,8 \\
\hline 7. & Selar & 80 & 2,4 \\
\hline 8. & Kembung & 91,5 & 2,7 \\
\hline 9. & Tongkol & 228 & 6,7 \\
\hline 10. & Lain-lain & 62 & 1,8 \\
\hline & Jumlah & $3.393,5$ & 100,0 \\
\hline
\end{tabular}


Tabel 4. Data hasil tangkapan pukat cincin mini menurut jumlah lampu dan ulangan

\begin{tabular}{ccccccccccc}
\hline $\begin{array}{c}\text { Perlakuan } \\
\text { jumlah } \\
\text { lampu }\end{array}$ & $\mathbf{1}$ & $\mathbf{2}$ & $\mathbf{3}$ & $\mathbf{4}$ & $\mathbf{5}$ & $\mathbf{6}$ & $\mathbf{7}$ & $\mathbf{8}$ & $\mathbf{9}$ & $\begin{array}{c}\text { Jumlah } \\
(\mathbf{k g})\end{array}$ \\
\cline { 2 - 12 } & $\mathbf{1 8 2}$ & 54 & 105,5 & 75 & 50 & 80 & 77 & 9 & 68 & 700,5 \\
7 & 227 & 59,5 & 119,5 & 23 & 55 & 176 & 562 & 85 & 23 & 1.330 \\
8 & 100 & 57 & 56 & 48 & 117 & 158 & 96 & 93 & 638 & 1.363 \\
\hline Jumlah & $\mathbf{5 0 9}$ & $\mathbf{1 7 0 , 5}$ & $\mathbf{2 8 1}$ & $\mathbf{1 4 6}$ & $\mathbf{2 2 2}$ & $\mathbf{4 1 4}$ & $\mathbf{7 3 5}$ & $\mathbf{1 8 7}$ & $\mathbf{7 2 9}$ & $\mathbf{3 . 3 9 3 , 5}$ \\
\hline
\end{tabular}

Tabel $5 . \quad$ Hasil analisis sidik ragam hasil tangkapan pukat cincin mini

\begin{tabular}{lccccc}
\multicolumn{1}{c}{ Sumber keragaman } & db & JK & KT & $\mathbf{F}_{\text {Hitung }}$ & $\begin{array}{c}\mathbf{F}_{\text {tabel }} \\
\mathbf{5} \%\end{array}$ \\
\hline Kelompok & 8 & 183.107 & 22.888 & $0,8858 \mathrm{~ns}$ & 2,59 \\
Perlakuan & 2 & 38.367 & 19.183 & $0,7424 \mathrm{~ns}$ & 3,63 \\
Galat & 16 & 413.407 & 25.837 & & \\
\hline Total & $\mathbf{2 6}$ & $\mathbf{6 3 4 . 8 8 1}$ & & & \\
\hline
\end{tabular}

Keterangan: $\mathrm{ns}=$ tidak berbeda nyata

\section{KESIMPULAN}

1. Total hasil tangkapan pukat cincin mini di perairan utara Jawa tengah pada bulan September 2004 $3.393,5 \mathrm{~kg}$ dengan laju tangkap (catch rate) 125,7 $\mathrm{kg}$ per tawur.

2. Komposisi hasil tangkapan didominasi oleh ikan tembang $(60,4 \%$ dari total hasil tangkapan keseluruhan), diikuti layur (11,3\%), cumi $(8,8 \%)$, tongkol $(6,7 \%)$, bawal $(3,0 \%)$, kembung $(2,7 \%)$, tetengkek $(2,2 \%)$, dan lain-lain (kurang dari $2 \%$ ).

3. Uji statistik menunjukkan penggunaan jumlah lampu 6, 7, dan 8 buah tidak berpengaruh nyata pada hasil tangkapan ikan.

4. Perubahan nilai intensitas cahaya di dalam air diduga sangat dipengaruhi oleh faktor alam terutama gelombang dan arus perairan.

\section{PERSANTUNAN}

Kegiatan dari hasil riset kinerja alat tangkap ikan pelagis yang menggunakan alat bantu cahaya ramah lingkungan di perairan pantai dan lepas pantai, T.A. 2004, di Balai Riset Perikanan Laut-Muara Baru, Jakarta.

\section{DAFTAR PUSTAKA}

Ayodhyoa. 1981. Metode penangkapan ikan. Yayasan Dewi Sri. Bogor.

Sadhotomo, B. \& M. Pottier. 1995. Exploratory scheme for the recruitment and migration of the main pelagic species. Biodynex, Pelfis ProjectCRIFI. 155-168.

Wijopriono, J. Durant, \& P. Gueguen. 1995. Seiners vessels: Current status and potential innovation. Seminar on Socio Economics, Innovation, and Management of the Small Pelagic Fishery of the Java Sea. Bandungan, Semarang. 4-7 December 1995. 